\title{
PENGUKURAN PERSEPSI DOSEN FAKULTAS TEKNIK TENTANG IMPLEMENTASI REMUNERASI DI UNIVERSITAS PATTIMURA
}

\author{
Alfredo Tutuhatunewa ${ }^{1, *}$, Ariviana L. Kakerissa ${ }^{2}$, Tradessantia Syatauw ${ }^{3}$ \\ 1Jurusan Teknik Industri Fakultas Teknik Universitas Pattimura, Ambon 97233 \\ *Email: alfredo.tutuhatunewa@fatek.unpatti.ac.id \\ 2Jurusan Teknik Industri Fakultas Teknik Universitas Pattimura, Ambon 97233 \\ Email: vianakakerissa71@gmail.com \\ 3Jurusan Teknik Industri Fakultas Teknik Universitas Pattimura, Ambon 97233 \\ Email: tsyatauw@gmail.com
}

\begin{abstract}
Abstrak. Penelitian bertujuan untuk mengetahui persepsi dosen Fakultas Teknik, terhadap kebijakan implementasi remunerasi pada Universitas Pattimura.Persepsi terkait implementasi remunerasi dapat diukur dari beberapa indikator, antara lain penetapan grading, penetapan tarif, sistem pelaporan kinerja, sistem penghargaan, sistem penilaian kinerja serta pengalaman dan masa kerja. Analisis dilakukan dengan klasterisasi menggunakan $K$-mean cluster. Hasil penelitian menunjukkan bahwa dari tiga klaster yang dibentuk, memiliki perbedaan yang signifikan, dengan persepsi yang tinggi, sedang dan rendah. Keterbatasan penelitian dan usulan penelitian lanjutan dibahas pada bagian akhir makalah ini.
\end{abstract}

Kata kunci: klaster, persepsi, remunerasi.

\begin{abstract}
This study aims to determine the perception of lecturers of the Faculty of Engineering on the policy of implementing remuneration at the Pattimura University. Perceptions related to remuneration implementation can be measured from several indicators, including grading determination, tariff setting, performance reporting system, reward system, performance appraisal system as well as experience and years of service. The analysis was carried out by clustering using $K$-mean cluster. The results showed that of the three clusters formed, there were significant differences, with high, medium and low perceptions. The limitations of the study and suggestions for further research are discussed at the end of this paper.
\end{abstract}

Keywords: cluster, perception, remuneration.

\section{PENDAHULUAN}

Kebijakan remunerasi di Universitas Pattimura telah dilaksanakan sejak bulan Juni 2019, termasuk Fakultas Teknik. Kebijakan ini menimbulkan persepsi yang berbeda-beda bagi sebagian besar dosen.

Remuneration memiliki kata dasar remunerate yang berarti membayar atau juga dapat disebut mengupahi [1]. Dalam praktiknya remunerasi diberikan kepada pegawai atas dasar adanya hubungan kerja, dimana ketika suatu pekerjaan telah diselesaikan maka remunerasi dapat diterima.

Tujuan penelitian ini adalah untuk mengukur persepsi dosen Fakultas Teknik tentang implementasi remunerasi di Fakultas Teknik Unpatti.

Persepsi terkait implementasi remunerasi dapat diukur dari beberapa indikator, antara lain penetapan grading, penetapan tarif, sistem pelaporan kinerja, sistem penghargaan, sistem penilaian kinerja serta pengalaman dan masa kerja [2].

\section{Penetapan Grading dan Tarif Remunerasi}

Grading merupakan tingkatan tarif remunerasi yang diklasifikasikan berdasarkan hasil evaluasi jabatan.Grading atau kelas jabatan ditetapkan berdasarkan proses evaluasi jabatan yang menghasilkan nilai jabatan berupa skor kuantitatif. 


\section{Kinerja dan Penilaian Kinerja}

Kinerja merupakan ukuran ketercapaian atas target dari suatu pekerjaan[2]. Untuk mengetahui berapa capaian kinerja yang diperoleh sesorang maka perlu dilakukan evaluasi atau penilaian kinerja. Evaluasi kinerja adalah suatu metode dan proses penilaian pelaksanaan tugas(performance), sesuai dengan standar kinerja yang ditetapkan lebih dahulu[3]. Sementara itu, Uno dan Lamatenggo[4]berpendapat bahwaevaluasi kinerja adalah proses mengukur kinerja seseorang dengan cara membandingkan dengan standar, target/sasaran, atau kriteria yangtelah ditetapkan terlebih dahulu atau sudah disepakati bersama.

Prinsip dasar yang penting untuk diketahui dalam penyusunan remunerasi[5], yaitu:

1) Adil dan Proporsional

Adil tidak berarti bahwa setiap karyawan menerima upah atau gaji yang sama, namun juga harus mempertimbangkan kondisi perusahaan dan kebutuhan pekerja. Di sisi perusahaan. Adil dan proporsional berkaitan dengan kondisi keuangan perusahaan dan kecenderungan pasar di masa mendatang, sedangkan di sisi pekerja, adil adalah tercukupinya pendapatan yang dapat memenuhi kebutuhan pekerja maupun keluarganya. Asas adil sangat penting karena didapat dalam rangka mewujudkan terciptanya suasana yang harmonis, motivasi kerja, semangat, disiplin, dan stabilitas perusahaan.

2) Layak dan Wajar

Batasan pengertian layak dan wajar itu relative. Bisa saja di sisi pekerja mengatakan bahwa remunerasi yang didapat belum memenuhi kebutuhan pekerja dan keluarganya, sedangkan pihak pengusaha sudah memastikan bahwa apa yang telah diberikan sudah memenuhi kesejahteraan. Parameter yang digunaan untuk menetapkan remunerasi karyawan di perusahaan, yaitu ketentuan normatif yang ditetapkan melalui peraturan perundang-undangan.

3) Tepat

Sistem remunerasi kepada pekerja didasarkan pada kinerja karyawan. Hasil kerja karyawan dievaluasi dan dinilai dengan mengacu pada parameter yang telah ditetapkan. Hasil penilaian tersebut menentukan berapa seharusnya remunerasi yang tepat untuk diterima karyawan tersebut.

4) Kompetitif

Dapat bersaing dengan perusahaan lain seperti perusahaan yang menghasilkan produk sejenis atau lokasi perusahaan yang berdekatan agar tidak terjadi saling cemburu di antara sesama pekerja.

5) Transparan

Adanya keterbukaan dalam penetapan remunerasi. Dalam menetapkan syarat kenaikaan remunerasi harus diketahui dan mudah dipahami oleh karyawan.

Pada beberapa penelitian, remunerasi berpengaruh terhadap motivasi kerja, disiplin kerja dan kepuasan kerja karyawan di perusahaan [6], [7], atau rumah sakit [8]. Selain itu, remunerasi juga berpengaruh terhadap kepuasan kerja dan motivasi kerja pada perguruan tinggi [9], [10].

\section{BAHAN DAN METODE}

\subsection{Tipe Penelitian}

Tipe penelitian yang digunakan dalam penelitian ini adalah menggunakan metode kuantitatif dengan analisis cluster.

\subsection{Pengumpulan Data}

Pengumpulan data dilakukan dengan kuesioner Kuesioner digunakan untuk menanyakan hal-hal terkait implementasi pelaksanaan remunerasi di Fakultas Teknik Universitas Pattimura. Dalam penelitian ini digunakan kuesioner tertutup, dimana responden hanya memilih jawaban yang tersedia. Skala pengukuran yang digunakan dalam instrument ini adalah skala likert.Skala likert secara umum menggunakan peringkat lima angka penilaian yaitu, Sangat setuju (skor 5), Setuju (skor 4), Tidak pasti/netral (skor 3), Tidak setuju (skor 2), Sangat tidak setuju (skor 1).

Variabel penelitian terdiri dari [2]:

a. Persepsi terhadap proses penetapan grading (X1). Bagian ini berisi pernyataan mengenai bagaimana proses penetapan grading yang dilakukan tim implementasi remunerasi Universitas Pattimura. Hal yang dinilai adalah tentang penetapan grading, kesesuaian antara beban kerja dengan grading, serta kesesuaian tugas dan fungsi dengan grading.

b. Persepsi terhadap proses penetapan tarif (X2)

Bagian ini mempertanyakan persepsi dosen mengenai tarif remunerasi yang meliputi kesesuaian antara tarif remunerasi dengan beban kerja serta kebutuhan setiap dosen.

c. Persepsi terhadap sistem pelaporan kinerja (X3). Bagian ini menggambarkan persepsi dosen terhadap pemahaman pengisian laporan kinerja dan sosialisasi tentang mekanisme pelaporan kinerja yang dilakukan oleh tim implementasi remunerasi.

d. Persepsi terhadap sistem penghargaan (X4). 
Sistem penghargaan adalah bagaimana pencapaian kinerja yang melebihi target patut diapresiasi, yang diberikan berupa bonus agar dapat meningkatkan kinerja dosen.

e. Persepsi terhadap sistem penilaian kinerja (X5) Bagian ini mempertanyakan persepsi dosen terhadap besarnya pengaruh unsur-unsur penilaian kinerja terhadap capaian remunerasi yang diperoleh.

f. Persepsi terhadap pengalaman dan masa kerja (X6). Bagian ini mempertanyakan persepsi dosen terhadap pemberian remunerasi yang berdasar pada banyaknya pengalaman dan lamanya masa kerja.

\subsection{Metode Analisis Data}

Uji validitas. Dilakukan untuk mengetahui kelayakan butir-butir dalam suatu daftar (konstruk) pertanyaan dalam mendefinisikan suatu variabel. Suatu butir pertanyaan dikatakan valid jika nilai rhitung yang merupakan nilai dari corrected itemtotal correlation > dari r-tabel yang diperoleh melalui Df (Degree of Freedom).

Uji Reliabilitas merupakan ukuran suatu kestabilan dan konsistensi responden dalam menjawab hal yang berkaitan dengan konstrukkonstruk pertanyaan yang merupakan dimensi suatu variabel dan disusun dalam suatu bentuk kusioner. Alat ukur yang akan digunakan adalah cronbach alpha. Reliabilitas suatu konstruk variable dikatakan baik jika memiliki nilai cronbach alpha $>0,60$.

Proses pengklasteran dilakukan dengan SPSS, yaitu dengan $K$-Mean Cluster. Data kuesioner akan distandarisasi dengan merubahnya menjadi data $z$ score. Selanjutnya dilakukan analisis terhadap klaster yang terbentuk, sehingga diperoleh Final cluster center. Selanjutnya dihitung skor masingmasing variabel untuk tiap klaster, dengan menggunakan persamaan:

$$
X=\mu+z \sigma
$$

Dimana:

$$
\begin{aligned}
X= & \text { rata-rata sampel/data/variabel dalam kluster } \\
& \text { tertentu } \\
\mu= & \text { rata-rata populasi } \\
\sigma= & \text { standard deviasi } \\
z= & \text { nilai } z \text {-score }
\end{aligned}
$$

Uji Perbedaan rata-rata dilakukan untuk menganalisis ada atau tidaknya perbedaan signifikan antara nilai rata-rata klaster satu dengan klaster lain yang terbentuk. Uji perbedaan rata-rata dilakukan dengan Uji F. Hipotesis yang digunakan dalam pengujian ini adalah:
- H0: $\mu 1=\mu 2=\mu 3=\ldots=\mu n$, Tidak terdapat perbedaan signifikan antara rata-rata hitung dari n klaster.

- H1: $\mu 1 \neq \mu 2 \neq \mu 3 \neq \ldots \neq \mu$ n, Ada perbedaan yang signifikan antara rata-rata hitung dari $n$ klaster.

Tolak hipotesis nol (H0) jika nilai p-value $<0.05$.

\section{HASIL DAN PEMBAHASAN 3.1. Sampel Penelitian}

Berdasarkan data, jumlah seluruh dosen Fakultas Teknik adalah sebanyak 71 dosen. Jumlah sampel yang diambil sebanyak 42 orang, dengan komposisi pada Tabel 1.

Tabel 1. Komposisi Responden

\begin{tabular}{clc}
\hline No. & Responden & Jumlah \\
\hline 1 & Pimpinan Fakultas & 7 \\
2 & Ketua Prodi & 4 \\
\hline 3 & Dosen biasa & 31 \\
\hline & Jumlah & 42 \\
\hline
\end{tabular}

\subsection{Uji Validitas}

Hasil uji validitas item pertanyaan pada kuesiner ditunjukan pada Tabel 2.

Tabel 2. Hasil Uji Validitas

\begin{tabular}{cccc}
\hline & \multicolumn{3}{c}{ Total } \\
& $\begin{array}{c}\text { Pearson } \\
\text { Correlation }\end{array}$ & $\begin{array}{c}\text { Sig. } \\
\text { (2-tailed) }\end{array}$ & $N$ \\
\hline X1 & $0,746^{* *}$ & 0,000 & 42 \\
X2 & $0,776^{* *}$ & 0,000 & 42 \\
X3 & $0,793^{* *}$ & 0,000 & 42 \\
X4 & $0,470^{* *}$ & 0,002 & 42 \\
X5 & $0,888^{* *}$ & 0,000 & 42 \\
X6 & $0,681^{* *}$ & 0,000 & 42 \\
\hline
\end{tabular}

Hasil uji validitas menunjukkan bahwa semua item pertanyaan dinyatakan valid.

\subsection{Uji Reliabilitas}

Reliabilitas suatu konstruk variabel dikatakan baik jika memiliki nilai cronbach alpha> 0,60. Hasil uji reliabilitas dapat dilihat pada Tabel 3.

Tabel 3 Hasil Uji Reliabilitas

\begin{tabular}{cc}
\hline Cronbach's Alpha & N of Items \\
\hline 0,821 & 6 \\
\hline
\end{tabular}

Tabel 3 menunjukan nilai cronbach alpha yang diperoleh sebesar 0,821 sehingga dapat dinyatakan instrumen penelitian telah reliabel. 


\subsection{Analisis Klaster}

Analisis klaster dilakukan untuk mengelompokkan obyek berdasarkan ciri-ciri atau karakteristik yang dimiliki. Pengelompokkan obyek ini bisa berdasarkan ciri-ciri pada responden berdasarkan persepsi terhadap remunerasi. Analisis dilakukan dengan K-Mean Cluster. Analisis didahului dengan membuat standarisasi terhadap data kuesioner, dengan cara membuat nilai z-score. Statistik deskriptif ditunjukkan pada Tabel 4.

Tabel 4. Statistik deskriptif

\begin{tabular}{cccccc}
\hline & N & Min. & Max. & Mean & $\begin{array}{c}\text { Std. } \\
\text { Deviation }\end{array}$ \\
\hline X1 & 42 & 1,00 & 5,00 & 3,2619 & 0,88509 \\
X2 & 42 & 1,00 & 5,00 & 2,9167 & 0,84042 \\
X3 & 42 & 1,00 & 5,00 & 3,3690 & 1,03039 \\
X4 & 42 & 1,00 & 5,00 & 4,5476 & 0,83235 \\
X5 & 42 & 1,33 & 5,00 & 3,2460 & 0,86816 \\
X6 & 42 & 1,50 & 4,50 & 3,0357 & 0,75217 \\
Valid N & 42 & & & & \\
(listwise) & & & & & \\
\hline
\end{tabular}

Pada Tabel 4, dapat dilihat nilai rata-rata dari masing-masing variabel. Nilai rata-rata tertinggi ada pada variabel persepsi responden terhadap sistem penghargaan (X4), yaitu sebesar 4,5476. Sementara, nilai rata-rata terendah adalah variabel persepsi terhadap proses penetapan tarif (X2), sebesar 2,9167.

Tabel 5. Keanggotaan Klaster

\begin{tabular}{cccc}
\hline Responden & Klaster & Responden & Klaster \\
\hline 1 & 3 & 22 & 1 \\
2 & 3 & 23 & 1 \\
3 & 3 & 24 & 3 \\
4 & 3 & 25 & 3 \\
5 & 1 & 26 & 1 \\
6 & 1 & 27 & 1 \\
7 & 1 & 28 & 1 \\
8 & 1 & 29 & 2 \\
9 & 1 & 30 & 1 \\
10 & 1 & 31 & 1 \\
11 & 1 & 32 & 3 \\
12 & 1 & 33 & 1 \\
13 & 1 & 34 & 2 \\
14 & 1 & 35 & 1 \\
15 & 1 & 36 & 3 \\
16 & 1 & 37 & 3 \\
17 & 1 & 38 & 3 \\
18 & 3 & 39 & 1 \\
19 & 1 & 40 & 3 \\
20 & 1 & 41 & 2 \\
21 & 3 & 42 & 1 \\
\hline
\end{tabular}

Hasil pengelompokkan obyek ke dalam 3 cluster, menyebabkan pembagian keanggotaan cluster seperti pada Tabel 5. Terdapat 26 anggota cluster 1, 3 anggota cluster 2 dan 13 anggota cluster 3.

Tabel Final cluster center ditunjukkan pada Tabel 6. Untuk menafsirkan tabel hasil analisis dengan ketentuan sebagai berikut: (1) Jika nilainya negatif berarti klaster yang bersangkutan ada di bawah rata-rata total; dan (2) Jika nilai positif berarti klaster yang bersangkutan ada di atas ratarata populasi.

Nilai rata-rata setiap variabel dihitung dengan persamaan (1), dimana hasilnya ditunjukkan pada Tabel 7. Perbedaan nilai rata-rata setiap variabel untuk masing-masing klaster, ditunjukan pada Gambar 1.

Tabel 6. Final Cluster Center

\begin{tabular}{lccl}
\hline & \multicolumn{3}{c}{ Klaster } \\
\cline { 2 - 4 } & 1 & 2 & \multicolumn{1}{c}{3} \\
\hline Zscore(X1) & 0,47179 & $-1,67680$ & $-0,55663$ \\
Zscore(X2) & 0,53392 & $-1,68567$ & $-0,67884$ \\
Zscore(X3) & 0,59368 & $-1,49042$ & $-0,84342$ \\
Zscore(X4) & 0,08142 & $-2,66030$ & 0,45108 \\
Zscore(X5) & 0,60265 & $-1,81920$ & $-0,78548$ \\
Zscore(X6) & 0,33602 & $-1,82012$ & $-0,25202$ \\
\hline
\end{tabular}

Tabel 7. Hasil perhitungan skor

\begin{tabular}{cccc}
\hline \multirow{2}{*}{ Variabel } & \multicolumn{3}{c}{ Klaster } \\
\cline { 2 - 4 } X1 & 1 & 2 & 3 \\
\hline X2 & 3,679 & 1,778 & 2,769 \\
X3 & 3,365 & 1,500 & 2,346 \\
X4 & 3,981 & 1,833 & 2,500 \\
X5 & 4,615 & 2,333 & 4,923 \\
X6 & 3,769 & 1,667 & 2,564 \\
\hline
\end{tabular}

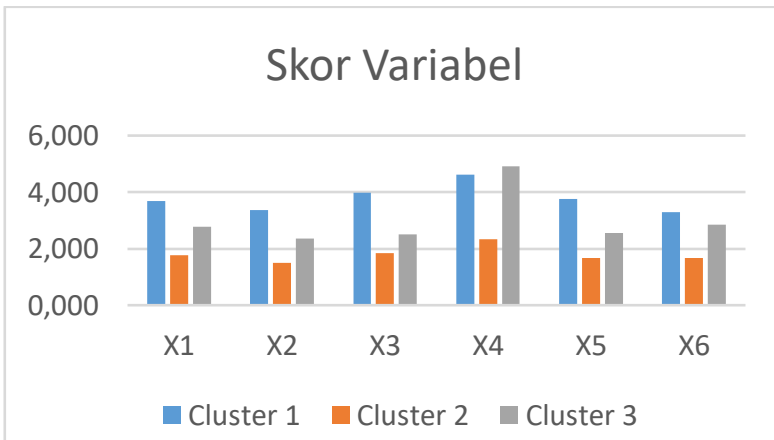

Gambar 1. Nilai rata-rataklaster

\subsection{Uji F}

Uji F dilakukan dengan berdasarkan Tabel 8, untuk melihat nilai $\mathrm{F}$ dan $\mathrm{p}$-value.

Berdasarkan Tabel 8, semua variabel memiliki nilai p-value atau taraf signifikan $0,000,(<0,05)$ sehingga dapat disimpulkan bahwa ketiga klaster 
yang terbentuk memiliki perbedaan yang signifikan untuk enam variabel yang diamati.

Tabel 8. Tabel Anova

\begin{tabular}{|c|c|c|c|c|c|c|}
\hline \multicolumn{7}{|c|}{ ANOVA } \\
\hline & \multicolumn{2}{|c|}{ Cluster } & \multicolumn{2}{|c|}{ Error } & \multirow[t]{2}{*}{$\mathrm{F}$} & \multirow[t]{2}{*}{ Sig. } \\
\hline & $\begin{array}{l}\text { Mean } \\
\text { Square }\end{array}$ & $\mathrm{df}$ & $\begin{array}{l}\text { Mean } \\
\text { Square }\end{array}$ & df & & \\
\hline Zscore $(\mathrm{X} 1)$ & 9,125 & 2 & 0,583 & 39 & 15,643 & 0,000 \\
\hline Zscore(X2) & 10,964 & 2 & 89 & 39 & 22,418 & 0,000 \\
\hline Zscore (X3) & 12,538 & 2 & 0,408 & 39 & 30,706 & 0,000 \\
\hline Zscore $(X 4)$ & 12,025 & 2 & 0,435 & 39 & 27,666 & 0,000 \\
\hline Zscore(X5) & 13,696 & 2 & 0,349 & 39 & 39,253 & 0,000 \\
\hline Zscore (X6) & 6,850 & 2 & 0,700 & 39 & 9,786 & 0,000 \\
\hline
\end{tabular}

The F tests should be used only for descriptive purposes because the clusters have been chosen to maximize the differences among cases in different clusters. The observed significance levels are not corrected for this and thus cannot be interpreted as tests of the hypothesis that the cluster means are equal.

\subsection{Pembahasan}

Untuk variabel Persepsi terhadap proses penetapan grading (X1), klaster 1 memiliki nilai rata-rata $(3,679)$ di atas rata-rata populasi $(3,2619)$. Hal ini menunjukkan bahwa klaster 1 merasa proses penetapan grading yang dilakukan telah sangat baik. Sebaliknya, klaster 2 dan klaster 3 memiliki nilai rata-rata di bawah rata-rata populasi (1,778 dan 2,769). Klaster 2 dan 3 adalah kelompok dosen yang memiliki persepsi bahwa proses penetapan grading belum dilakukan dengan baik, bahkan sangat buruk menurut klaster 2 .

Untuk variabel Persepsi terhadap proses penetapan tarif (X2), klaster 1 memiliki nilai ratarata $(3,365)$ di atas rata-rata populasi $(2,9167)$. Hal ini menunjukkan bahwa klaster 1 juga memiliki persepsi yang tinggi terhadap proses penetapan grading saat ini. Sementara itu, klaster 2 dan 3 juga menganggap proses ini belum dilakukan dengan baik, yang ditandai dengan nilai rata-rata kedua klaster ini (1,50 dan 2,346) yang kurang dari nilai rata-rata populasi.

Untuk variabel Persepsi terhadap sistem pelaporan kinerja (X3), klaster 1 memiliki nilai rata-rata 3,981 yang lebih tinggi dari nilai rata-rata populasi $(3,3690)$. Sementara, nilai rata-rata klaster $2(1,833)$ dan klaster $3(2,500)$, lebih kecil dari rata-rata populasinya. Hal ini menunjukkan bahwa klaster 1 memiliki persepsi yang baik terhadap pelaporan kinerja yang dilakukaan saat ini, tetapi klaster 2 dan klaster 3 memiliki persepsi yang sangat rendah terhadap variabel ini.

Variabel persepsi terhadap sistem penghargaan (X4) menunjukkan kondisi yang berbeda. Nilai rata-rata klaster $1(4,615)$ dan klaster $3(4,923)$ lebih tinggi dari rata-rata populasinya $(4,5476)$.
Sehingga, berdasarkan variabel sistem penghargaan ini, klaster 1 dan 3 mempersepsikan bahwa proses ini sudah sangat baik. Bahkan, ratarata klaster 3 juga berada pada posisi lebih tinggi dari klaster 1 . Sebaliknya, dengan nilai rata-rata 2,333, klaster 2 masih memiliki persepsi yang sangat rendah terhadap variabel ini.

Untuk variabel Persepsi terhadap sistem penilaian kinerja (X5), klaster 1 memiliki nilai rata-rata 3,769 , di atas rata-rata populasi sebesar 3,2460. Hal ini menunjukkan bahwa klaster 1 memiliki persepsi yang sangat tinggi terhadap sistem penilaian kinerja yang dialami saat ini. Di sisi lain, klaster 2 dan 3 memiliki nilai rata-rata lebih rendah $(1,667$ dan 2,564) dari nilai rata-rata populasi, yang menunjukkan bahwa klaster 2 dan klaster 3 memiliki persepsi yang rendah terhadap sistem penilaian kinerja saat ini.

Untuk variabel terakhir, Persepsi terhadap pengalaman dan masa kerja (X6), klaster 1 juga memiliki nilai rata-rata $(3,288)$ di atas nilai ratarata populasi $(3,0357)$, yang menunjukkan persepsi klaster 1 terhadap variabel ini sangat tinggi. sebaliknya, walaupun klaster 3 memiliki nilai ratarata yang cukup tinggi $(2,846)$, tetapi masih berada di bawah nilai rata-rata populasi. Sehingga, klaster 2 dan klaster 3 memiliki persepsi yang kurang baik terhadap variabel ini.

\section{KESIMPULAN}

Dari tiga klaster yang terbentuk, dapat disimpulkan bahwa klaster 1 yang beranggotakan 26 dosen, merupakan kelompok dosen yang memiliki persepsi paling tinggi terhadap implementasi remunerasi di Universitas Pattimura. Klaster 3 yag memiliki 13 dosen merupakan kelompok yang bisa dibilang rata-rata, walaupun semua nilai rata-rata masih di bawah nilai rata-rata populasi. Sementara klaster 2 yang terdiri dari 3 dosen, merupakan kelompok dosen yang memiliki persepsi sangat rendah terhadap implementasi remunerasi di Universitas Pattimura saat ini. Ketiga klaster berbeda secara signifikan untuk enam variabel yang diamati.

Penelitian ini hanya mengamati enam atribut persepsi responden terhadap implementasi remunerasi. Selain itu, sampel yang dipilih mungkin belum mewakili dosen secara keseluruhan. Penelitian lanjutan disarankan untuk mengkaji lebih banyak atribut persepsi yang mungkin berpengaruh, serta mempertimbangkan juga kesesuaian besar remunerasi dengan kebutuhan hidup layak. Selain itu, perlu dilanjutkan penelitian dengan menambah jumlah sampel agar hasilnya dapat digeneralisasi untuk seluruh populasi dosen Universitas Pattimura. 


\section{DAFTAR PUSTAKA}

[1] Roberia, "Analisis yuridis perbaikan sistem remunerasi pegawai negeri sipil Republik Indonesia," Tesis, Universitas Indonesia, Jakarta, 2009.

[2] Y. P. Senjani, "Analisis Implementasi Remunerasi BLU (Studi Kasus pada UIN Sunan Kalijaga Yogyakarta)," EkBis: Jurnal Ekonomi dan Bisnis, vol. 1, no. 1, Art. no. 1, Mar. 2017, doi:

10.14421/EkBis.2017.1.1.993.

[3] P. J. Simanjuntak, Manajemen dan Evaluasi Kinerja. Fakultas Ekonomi Universitas Indonesia, 2011.

[4] H. B. Uno and N. Lamatenggo, Teori Kinerja dan Pengukurannya. Bumi Aksara, 2012. Accessed: Jun. 21, 2021. [Online]. Available: /home/catalog/id/17064/slug/teori-kinerjadan-pengukurannya.html

[5] A. de Pora, Remunerasi: Kompensasi dan Benefit. Tanggerang: Parninta Offset, 2011.

[6] M. P. Satjanata and R. Saragih, "The effect of remuneration on employees performance at PT Hutama Karya (Persero)," e-Proceeding of Management, vol. 6, no. 2, pp. 4579-4589, Aug. 2019.

[7] E. Sardjana, S. Sudarmo, and D. G. Suharto, "The Effect of Remuneration, Work Discipline, Motivation on Performance," International Journal of Multicultural and Multireligious Understanding, vol. 5, no. 6, Art. no. 6, Jan. 2019, doi: 10.18415/ijmmu.v5i6.529.

[8] A. Mendes, R. J. Lunkes, L. Flach, and S. D. Kruger, "The influence of remuneration on the behavior of hospital employees in Brazil," Contaduría y Administración, vol. 62, no. 1, pp. 207-221, Jan. 2017, doi: 10.1016/j.cya.2016.04.005.

[9] W. A. Pratama and A. Prasetya, "Pengaruh sistem remunerasi terhadap kepuasan kerja dan motivasi kerja pada perguruan tinggi," Jurnal Administrasi Bisnis (JAB), vol. 46, no. 1, pp. 52-60, May 2017.

[10]O. Y. Calvin, "The Impact of Remuneration on Employees' Performance : A Study of Abdul Gusau Polytechnic, Talata-Mafara and State College of Education Maru, Zamfara State," AJBMR, vol. 4, no. 2, pp. 34-43, Mar. 2017, doi: 10.12816/0037554. 